\title{
Três espécies novas do gênero Chorisoneura (Blattellidae, Chorisoneuriinae) coletadas em ninhos de Sphecidae (Hymenoptera) do Estado do Acre, Brasil
}

\author{
Sonia Maria Lopes \& Edivar Heeren de Oliveira
}

\author{
Depto de Entomologia, Museu Nacional, Universidade Federal do Rio de Janeiro, Quinta da Boa Vista, São Cristóvão, 20940-040 \\ Rio de Janeiro, RJ, Brasil. (sonialf@acd.ufrj.br)
}

\begin{abstract}
Three new species of the genus Chorisoneura (Blattellidae, Chorisoneuriinae) collected in Sphecidae nests (Hymenoptera) from Acre State, Brazil. Three new species of Chorisoneura Brunner, 1865 from Acre State, Brazil collected in nests of Podium Fabricius, 1804 (Hymenoptera, Sphecidae) are described. Illustrations of genitalia are presented.
\end{abstract}

KEYWORDS. New species, Chorisoneura, Blattaria, taxonomy, Neotropical.

\section{INTRODUÇ̃̃O}

O gênero Chorisoneura Brunner, 1865 encontrase restrito à Região Neotropical, num total de 70 espécies já descritas, tendo sido coletadas no Brasil em todas as regiões geográficas (RoTH, 1998).

BRUNNER (1865) descreveu o gênero Chorisoneura com base na forma das asas, da placa subgenital e estilos, assinalando o gênero exclusivamente na América meridional, e designando como espécie-tipo Blatta nigrifrons Serville, 1839, do Brasil.

Rотн (1998) concordou com Brunner e limitou a distribuição geográfica do gênero às Américas do Sul, Central e Estados Unidos, posicionando-o na subfamília Pseudophyllodromiinae e revalidando o gênero Sorineuchora Caudell, 1927 que até então era considerado sinônimo de Chorisoneura.

As vespas da família Sphecidae caracterizam-se por serem solitárias e predadoras e os adultos são comumente encontrados nas flores; fazem seus ninhos em areia, solo seco, troncos secos ou apodrecidos, lama, solo sombrio, ninho de outras vespas ou colunas nas casas. Os representantes da subfamília Sphecinae são muito comuns, e as espécies do gênero Podium, de tamanho relativamente grande, abastecem seus ninhos com baratas (Rohart \& Menke, 1976).

Objetiva-se descrever três espécies novas do Estado do Acre, local até então inédito na literatura do gênero, coletadas em ninhos de vespas do gênero Podium Fabricius, 1804 (Hymenoptera, Sphecidae).

\section{MATERIAL E MÉTODOS}

Os exemplares foram coletados na Fazenda Experimental Catuaba, no Acre, um Centro Experimental da Universidade Federal do Acre, situado a $30 \mathrm{~km}$ da BR-364 em uma área de 800ha que apresenta diversidade de formas de uso da terra, incluindo antigos seringais, áreas de pastagem degradadas, florestas secundárias em diversos estágios de sucessão e florestas pouco alteradas. Nas áreas diretamente adjacentes ao longo das rochosas, predomina a pecuária extensiva, com grandes extensões de pastagens não produtivas e abandonadas. Os espécimes foram obtidos em ninhos de vespas da família Sphecidae e enviados ao Setor de Blattaria no Museu Nacional, Rio de Janeiro, com informações sobre o número do ninho onde foi coletado o material e a quantidade de exemplares em cada ninho. Dos exemplares que nos foram enviados separadamente em vidros contendo álcool $70 \%$, alguns estavam em bom estado e outros bastante danificados, seja pela ação de fungos nos ninhos, ou mesmo por já se encontrarem danificados pelas vespas.

As genitálias dos espécimens foram preparadas e examinadas em lâminas imersas em glicerina seguindo a metodologia utilizada por LOPEs \& Oliveira (2000). A terminologia adotada para genitália foi baseada em McKitTRICK (1964). Todo o material encontra-se depositado na coleção do Departamento de Entomologia do Museu Nacional (MNRJ).

\section{Chorisoneura catuabana sp. nov. \\ (Figs. 1-4)}

o. Coloração geral castanho-clara brilhante. Olhos negros. Tronco inicial de todas as nervuras das tégminas e base dorsal do arólio castanho mais escuro. Pulvilos esbranquiçados.

Cabeça triangular, olhos pequenos posicionados látero-anteriormente. Vértice exposto; espaço interocular amplo, igual à área que separa a base das inserções antenais. Antenas longas, filiformes e ciliadas; palpos maxilares ciliados, sendo o terceiro artículo maior que o quarto e o quinto dilatado na base, subigual em tamanho ao comprimento do quarto artículo.

Tórax com pronoto oval transversal, curto e alargado; abas laterais amplas, de contorno lateral arredondado; disco central amplo e arredondado. Tégminas longas ultrapassando o ápice dos cercos, afiladas, estreitando-se para o ápice. Pernas longas e espinhosas; fêmur I com a face ântero-ventral apresentando três a cinco espinhos médios até próximo 

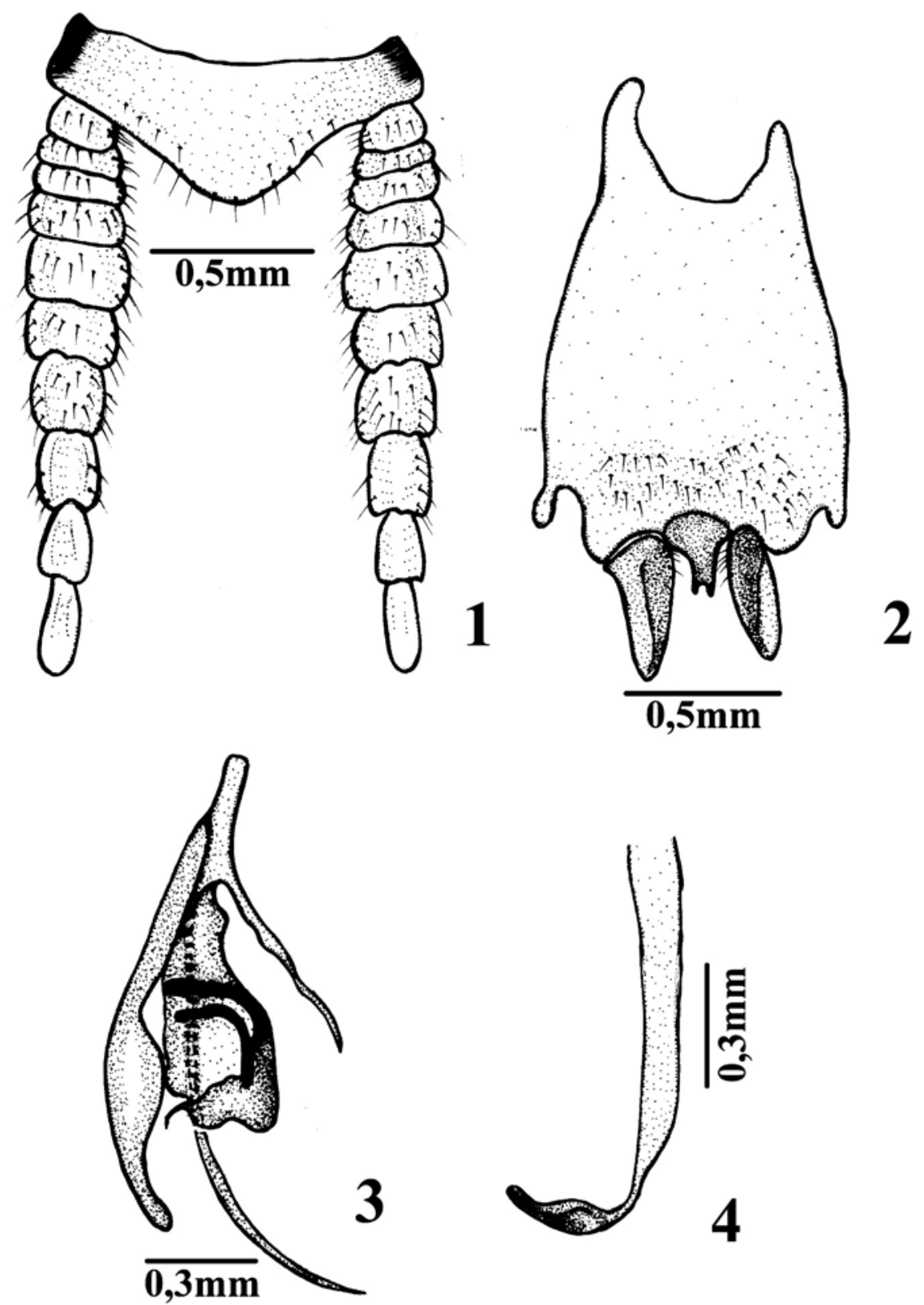

Figs. 1-4. Chorisoneura catuabana sp. nov., O: 1, placa supra-anal, dorsal; 2, placa subgenital, ventral; 3, falômero esquerdo (L1), dorsal; 4, falômero direito (R2), dorsal.

à região mediana, seguidos de uma série de diminutos espinhos até o ápice, com um espinho apical grande e desenvolvido; face póstero-ventral com espinhos médios espaçados; fêmur II com espinhos pequenos e espaçados na face ântero-ventral, terminando em um robusto apical; face póstero-ventral com espinhos pouco maiores, espaçados e um apical desenvolvido; fêmur III com espinhos médios e espaçados terminando em um apical desenvolvido nas faces ântero e póstero-ventral; pulvilos pouco desenvolvidos presentes em todos os artículos; arólios desenvolvidos; unhas assimétricas e simples.

Abdome com modificação tergal mediana no sétimo segmento, em forma circular e ciliada. Placa supra-anal pouco desenvolvida, ciliada, triangulóide sem reentrância mediana apical, com eixo transversal maior que o longitudinal, cercos longos e alargados (fig. 1). Placa subgenital simétrica, alargada na base com projeções látero-apicais; estilos lamelares, longos e pouco afilados apicalmente, separados por pequena projeção esclerotizada da placa subgenital (fig. 2). Falômero direito (R2) em forma de gancho, apicalmente com esclerotização interna (fig. 4); falômero esquerdo (L1) diferenciado com estruturas esclerotizadas afiladas (fig. 3).

Medidas, em mm, o. Comprimento total, 9,0; comprimento do pronoto, 1,5; largura do pronoto, 2,5; comprimento da tégmina, 8,5; largura da tégmina, 2,0.

Material-tipo. Holótipo ơ, BRASIL, Acre: Senador Guiomard (Reserva Catuaba), 10²'S 67³6'W, 17.VII.02, Elder F. Morato col. (ninho ${ }^{\circ}$ 1922/3) (MNRJ).

Etimologia. O nome da espécie é alusivo ao local onde foi coletado o exemplar. 
Diagnose. Chorisoneura catuabana sp. nov. difere das demais espécies pela configuração da estrutura mediana alargada entre os estilos na placa subgenital, pela placa supra-anal entre os cercos - que é mais pronunciada - e demais estruturas da genitália masculina.

\section{Chorisoneura fulgurosa sp. nov. (Figs. 5-12)}

๘. Coloração geral castanho-clara brilhante e hialina. Olhos negros. Coloração castanho-escura: (1) no vértice, com listras longitudinais em duas das quatro faixas transversais paralelas entre si, dispostas apicalmente entre os olhos; (2) na margem látero-posterior e disco central do pronoto (fig. 5); (3) no campo anal e (4) no ápice das tégminas. Coloração esbranquiçada em duas áreas da fronte, nas extremidades dos olhos próximo ao vértice, junto à gena e em duas faixas da cabeça.

Cabeça triangular, olhos pequenos posicionados látero-anteriormente; vértice exposto; espaço interocular amplo, medindo cerca de dois terços do espaço que separa a base das inserções antenais. Antenas longas, filiformes e ciliadas; palpos maxilares ciliados, terceiro artículo mais longo que o quarto, quinto artículo dilatado na base e subigual ao tamanho do quarto.

Tórax com pronoto oval, transversalmente curto e alargado; abas laterais amplas, de contorno lateral arredondado; disco central pequeno.Tégminas longas ultrapassando o ápice dos cercos, afilados, estreitandose para o ápice. Pernas longas e espinhosas; fêmur I apresentando cinco espinhos médios na face ânteroventral, até próximo à região mediana, seguidos por uma série de pequenos espinhos até o ápice, onde há um apical grande e robusto; face póstero-ventral com espinhos pequenos. Fêmures II e III com espinhos pequenos e espaçados na face ântero-ventral e um espinho apical desenvolvido; face póstero-ventral com espinhos pequenos. Pulvilos pouco desenvolvidos e presentes em todos os artículos tarsais; arólios presentes; unhas simples e assimétricas.

Abdome com modificação tergal mediana no sétimo segmento, em forma circular e ciliada (fig. 6). Placa supraanal pouco desenvolvida, ciliada, triangulóide com leve reentrância mediana apical, com eixo transversal maior que o longitudinal, cercos curtos e alargados (fig. 7). Placa subgenital simétrica, alargada no ápice; estilos lamelares, alargados, espatulados, arredondados apicalmente, com pequena projeção esclerotizada da placa subgenital entre eles (fig. 8). Falômero direito (R2) em forma de gancho, apicalmente com esclerotização interna (fig. 10); falômero esquerdo (L1) diferenciado, com estruturas esclerotizadas medianamente e uma das extremidades terminando em formas espinhosas (fig. 12); esclerito mediano (L2vm) longo, ápice do esclerito mediano (L2d) com uma das extremidades membranosa e outra muito afilada no ápice, marginada com espinhos diminutos (fig. 11). Esclerito do falômero direito alongado, com extremidade acuminada (fig. 9).

Medidas, em mm, or. Comprimento total, 11,5; comprimento do pronoto, 2,5; largura do pronoto, 3,5; comprimento da tégmina, 9,5 ; largura da tégmina, 3,0 .

Material-tipo. Holótipo ơ, BRASIL, Acre: Senador
Guiomard (Reserva Catuaba), 10 $0^{\circ}$ 'S 67 $67^{\circ}$ 'W, 17.VII.02, Elder F. Morato col. (ninho $\left.\mathrm{n}^{\circ} 1922 / 3\right)(\mathrm{MNRJ})$.

Etimologia. O nome da espécie faz referência à coloração e brilho do pronoto.

Diagnose. Espécie similar a Chorisoneura fulva Rocha e Silva \& Aguiar, 1977 e C. bella Rocha e Silva \& Aguiar, 1977, diferindo destas e das demais espécies do gênero por detalhes de coloração na cabeça e no pronoto, pela configuração da estrutura mediana entre os estilos, pela placa supra-anal com pequena reentrância mediana entre os cercos e pelo esclerito mediano (L2vm) e falômero esquerdo (L1).

\section{Chorisoneura mimosa sp. nov. (Figs. 13-18)}

đ. Coloração geral castanho-clara brilhante. Olhos escuros, quase negros. Coloração castanho-escura em uma faixa transversal estreita no vértice da cabeça, no tronco inicial de todas as nervuras e uma pequena área do ápice da tégmina. Vértice da cabeça com uma faixa estreita quase branca, paralela à anterior; fronte com áreas mais claras. Pronoto com disco central sem manchas.

Cabeça triangular, vértice exposto; olhos posicionados látero-anteriormente; espaço interocular amplo, subigual ao espaço que separa a base das inserções antenais; antenas longas, filiformes e ciliadas; palpos maxilares ciliados bem desenvolvidos, com o terceiro artículo maior que o quarto, quinto dilatado, comprimento subigual ao quarto. Palpos labiais ciliados.

Tórax com pronoto oval, transversal, curto e alargado; abas laterais amplas, com as margens laterais arredondadas; disco central amplo e circular. Tégminas longas, ultrapassando o ápice do abdome, afiladas, estreitando para a extremidade. Pernas longas e espinhosas. Fêmur I com três ou cinco espinhos médios próximos à base, na face ântero-ventral, seguidos de uma série de diminutos espinhos até o ápice, com um apical robusto; face póstero-ventral com espinhos médios, dispostos espaçadamente. Fêmures II e III, na face ântero-ventral, com espinhos pequenos e espaçados e, na face póstero-ventral, espinhos pouco maiores e mais aproximados. Pulvilos pouco desenvolvidos em todos os artículos tarsais; arólios desenvolvidos, unhas assimétricas e simples.

Abdome com modificação tergal mediana no sétimo segmento, em forma circular e ciliada (fig. 13). Placa supraanal pouco desenvolvida, ciliada, triangulóide sem reentrância mediana apical, com eixo transversal maior que o longitudinal, cercos curtos e alargados (fig. 14). Placa subgenital simétrica, alargada no ápice, com projeções látero-apicais; estilos situados medianamente no ápice da placa, lamelares, longos e afilados apicalmente, com pequena projeção esclerotizada e espiniforme entre eles (fig. 15). Falômero direito (R2) em forma de gancho, com esclerotização interna apical (fig. 18); falômero esquerdo (L1) diferenciado com estruturas esclerotizadas medianamente (fig. 16); esclerito mediano (L2vm) longo, ápice do esclerito mediano (L2d) com uma das extremidades membranosa e a outra afilada no ápice e o contorno com espinhos diminutos (fig. 17). Medidas, em mm, o. Comprimento total, 8,0; 

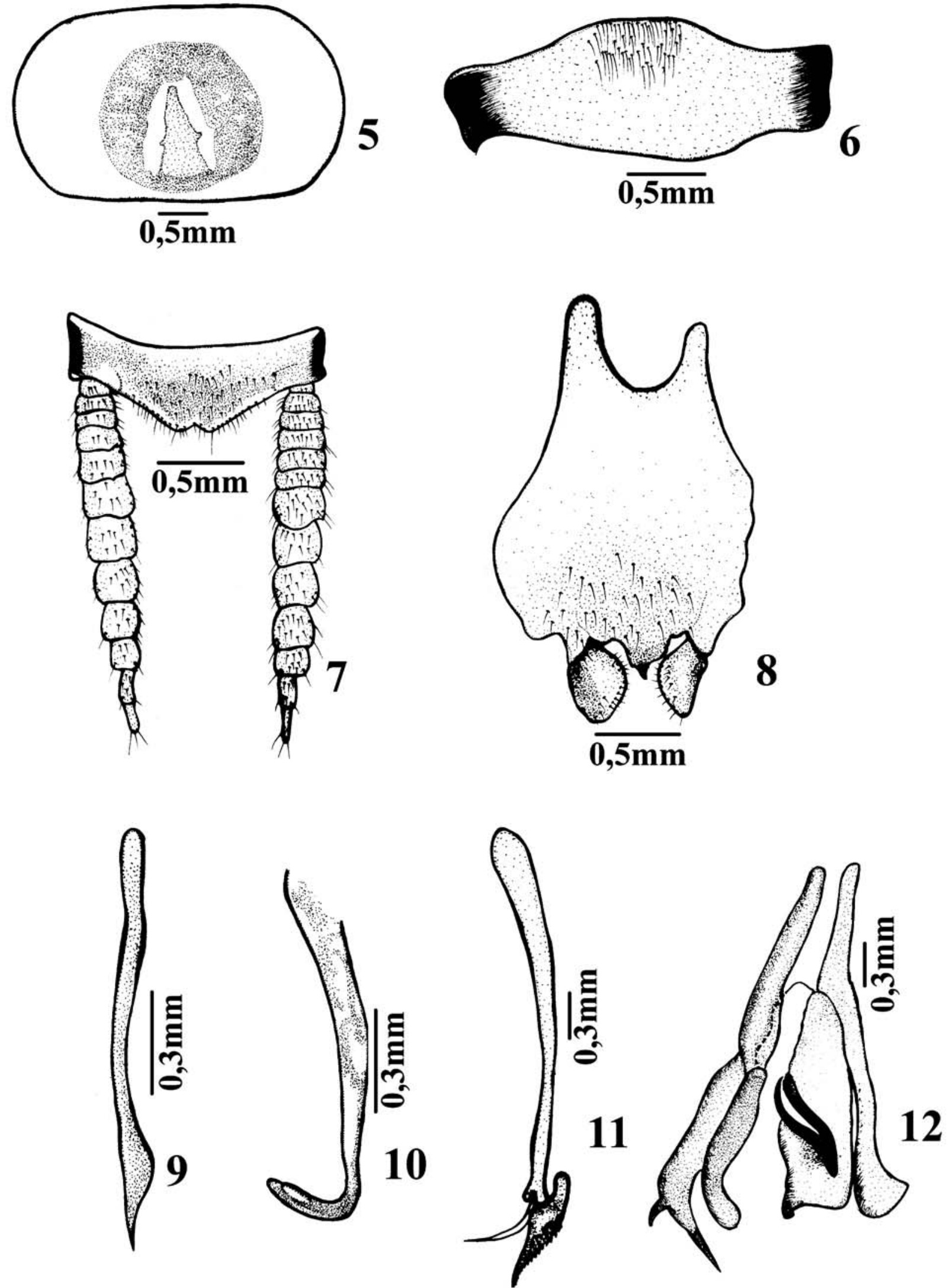

Figs. 5-12. Chorisoneura fulgurosa sp. nov., o: 5, pronoto, dorsal; 6, modificação tergal no sétimo segmento abdominal, dorsal; 7, placa supra-anal, dorsal; 8, placa subgenital, ventral; 9, esclerito do falômero direito, dorsal; 10, falômero direito (R2), dorsal; 11, esclerito mediano (L2vm), dorsal; 12, falômero esquerdo (L1), dorsal. 

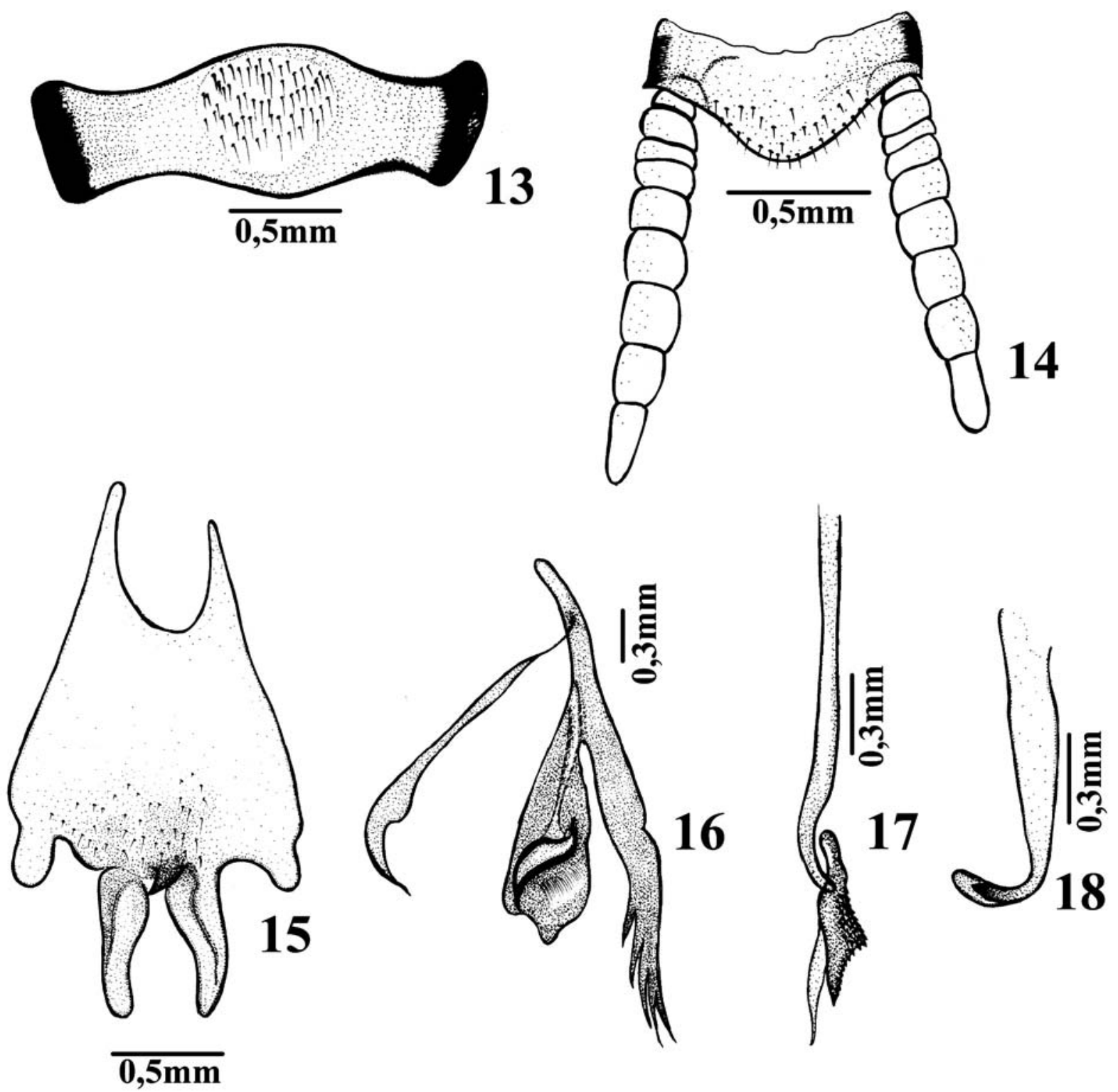

Figs. 13-18. Chorisoneura mimosa sp. nov., o': 13, modificação tergal no sétimo segmento abdominal, dorsal; 14, placa supra-anal, dorsal; 15, placa subgenital, ventral; 16, falômero esquerdo (L1), dorsal; 17, esclerito mediano (L2vm), dorsal; 18, falômero direito (R2), dorsal.

comprimento do pronoto, 1,5 ; largura do pronoto, 2,5 ; comprimento da tégmina, 7,0 ; largura da tégmina, 2,0 .

Material-tipo. Holótipo ơ, BRASIL, Acre: Senador Guiomard (Reserva Catuaba), 104'S 67³6'W, 17.VII.2002, Elder F. Morato col. (ninho $\mathrm{n}^{\circ}$ 1921/1) (MNRJ).

Etimologia. O nome da espécie faz referência ao tamanho pequeno do exemplar.

Diagnose. Chorisoneura mimosa sp. nov. é similar a C. sinop Rocha e Silva \& Aguiar, 1977, porém difere desta e das demais espécies do gênero pela configuração da região mediana da placa subgenital entre os estilos e pela formação das estruturas genitais do falômero esquerdo (L1) e esclerito mediano (L2vm).

Discussão taxonômica. As três espécies novas descritas distinguem-se entre si por caracteres morfológicos genitais. Chorisoneura catuabana difere das outras duas (1) pela estrutura mediana alargada entre os estilos na placa subgenital; (2) pela placa supra-anal mais proeminente entre os cercos; (3) pelos estilos da placa subgenital simples e lamelares. C. fulgurosa e $C$. mimosa diferem de C. catuabana (1) pela proeminência mediana entre os estilos, em forma de espinho; (2) $C$. fulgurosa apresenta estilos arredondados e menores na placa subgenital; (3) em C. mimosa os estilos são mais alongados e a proeminência mediana da placa subgenital é mais evidenciada.

Agradecimentos. À Dra. Janira Martins Costa (MNRJ) pelo apoio técnico. Ao Prof. Elder Ferreira Morato, Universidade Federal do Acre, pelo material coletado.

\section{REFERÊNCIAS BIBLIOGRÁFICAS}

Brunner, C. 1865. Nouveau Système Des Blattaires. Vienna, G. Braumüller. 426p. 
Lopes, S. M. \& Oliveira, E. H. 2000. Espécie nova de Blaberus Serville, 1831 do Estado de São Paulo, Brasil (Blaberidae, Blaberinae). Boletim do Museu Nacional, Nova Série, Zoologia, Rio de Janeiro, 415:1-4.

McKittrick, F. A. 1964. Evolutionary studies of cockroaches. Cornell Experiment Station Memoir, Ithaca, 389:1-197. Rohart, R. M. \& Menke, A. S. 1976. Sphecid wasps of the world: a generic revision. Berkeley, University of Chicago Press. 695p.

Rотн, L. M. 1998. The cockroaches genera Chorisoneura Brunner, Sorineuchora Caudell, Chorisoneurodes Princis and Chorisoserrata, gen. nov. (Blattaria: Blattellidae: Pseudophyllodromiinae). Oriental Insects, Gainesville, 32:1-33 